\title{
STATISTICAL ANALYSIS OF INFLUENCING FACTORS ON EDDY CURRENT MEASUREMENT SYSTEM
}

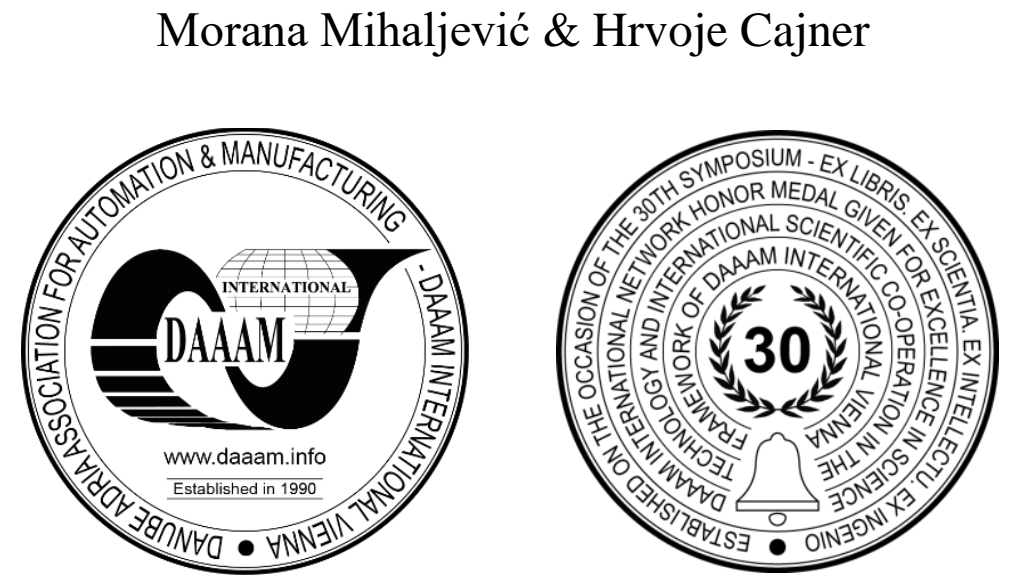

This Publication has to be referred as: Mihaljevic, M[orana] \& Cajner, H[rvoje] (2019). Statistical Analysis of Influencing Factors on Eddy Current Measurement System, Proceedings of the 30th DAAAM International Symposium, pp.0305-0310, B. Katalinic (Ed.), Published by DAAAM International, ISBN 978-3-902734-22-8, ISSN 1726-9679, Vienna, Austria

DOI: $10.2507 / 30$ th.daaam.proceedings.040

\begin{abstract}
The quality control of coating is regularly based on visual inspection and thickness measurement results using non destructive measurement system. In practice, coating quality control is performed after the coating is applied and during the exploitation life of the structural component. The coating quality is usually evaluated in accordance with the standard requirements, internal standards and technical specification. In this paper the thickness of electrically non-conductive coating on non-ferromagnetic, electrically conductive metal substrates measurements were demonstrated. Eddy current measurement method was applied to measure the coating thickness on aluminium substrate. The prepared samples consist of three different layer thicknesses. On each layer measurements were conducted under repeatability conditions $(n=5)$. The measurements were performed by one person with two different measurement system at the same measurement condition. With the scope to determine the significance of the three selected effects (Coating thickness, Measurement system and Measurement spot) the ANOVA method were used. For the representative comparison of two measurement system the true value of each coating thickness was determined by means of image analysis software for metallographic specimens.
\end{abstract}

Keywords: coating; eddy current; non-destructive measurement system; quality control.

\section{Introduction}

Quality control tools are mainly applied for pre-service and in-service inspections of coating thicknesses with the scope to ensure the integrity and reliable exploitation of the component. In that sense of great importance is to provide precisely and accurately measurement results. The best measurement results are obtained when all impact factors on measurement results are under control. In order to provide certain level of confidence in coating thickness measurement results, measurement comparisons are usually carried out. Repeatability and reproducibility (R\&R) is a tool that are commonly utilised in analysis of capability of processes.

Coatings for surface protection is the most common form of steel structures protection to ensure that products are protected against corrosion. 
Depending on the application of construction, different coating types are applied in different methods, colours and thicknesses. Accordingly, the coating properties effect on the construction durability in exploitation time.

Surface coating is usually used to ensure a specific segment of construction that is exposed to harsh and corrosive environments [1], [2]. Coating properties effect on durability of the construction during the time of exploitation. Quality control of coating thickness is applied after the coating application and during the construction segment exploitation. Furthermore, the coating quality assessment should be in accordance with standards and requirements. Quality control of coatings is based on visual surface inspection and the coating thickness measurement results as well. Since the result of coating thickness measurement is quantitative it belongs to a field of metrology. From the metrology point of view, every measurement is prone to error and is often stated that a measurement result is complete only when accompanied by a quantitative statement of its uncertainty [3]. Unfortunately, in practice, when coating thickness measurement is applied as a quality control tool, personnel omit to display the measurement results with associated measurement uncertainty. In general, the uncertainty of the measurement result arises from the uncertainties of all impact factors in the selected measurement system [4].

The main scope of the paper is to examine the possibility of peer comparison of two measurement systems that are commonly applied for measuring the coating thickness by eddy current method. Furthermore, in this paper it is investigated which one of the three selected factors (Coating thickness, Measurement system and Measurement spot) significantly contributes to the uncertainty of the measurement results. The measurements were performed on prepared sample which has three different organic coating thicknesses on aluminium substrate.

In general, the measuring equipment is essential for achieving the accurate and precise measurement results and therefore it has important role in any measurement system [5]. Thus, for the further research the impact of individual elements of measurement system should be investigated [6].

\section{Measurement method and experiment design}

The eddy current method is a non-destructive method commonly used for inspection specific near surface nonhomogeneities in conductive materials [7]. The probe (coil) that is in contact with the surface induce a magnetic field into conductive material where non-homogeneities in the material create changes to the "eddy currents". This method is also commonly used for a coating thickness measurement to measure the thickness of an electrically non-conductive coating on non-ferromagnetic, electrically conductive metal substrates. The measurement is based on the difference in electrical conductivity between the coating and the substrate.

In this research measurements were conducted on aluminium plate with dimensions of 350 x $290 \mathrm{~mm}$. Nominal thickness of aluminium substrate is $5 \mathrm{~mm}$. With the scope to ensure representability of sample data 5 different measurement spots are selected and statistical analysis by means of ANOVA method was performed [8], [9]. Measurements were conducted with two different measurement system commonly used in the process of coating thickness quality control by eddy current method.

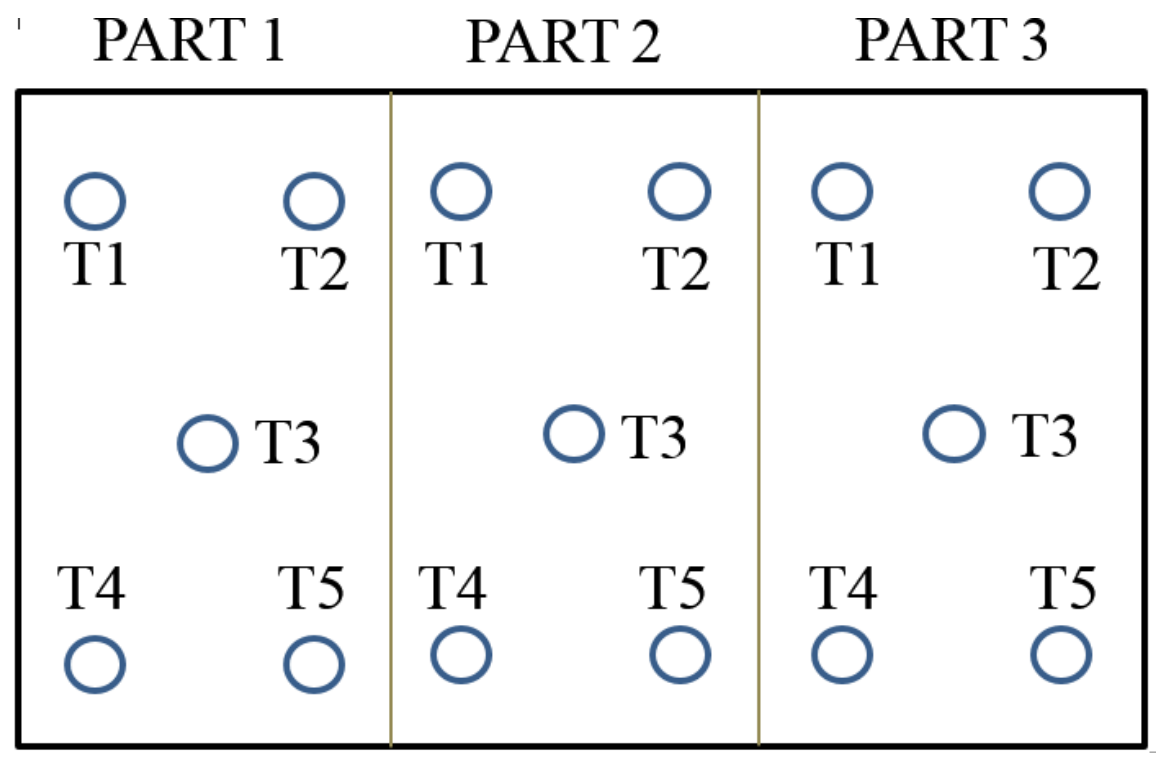

Fig. 1. Selected measurement spots on aluminium substrate

In order to assure best statistical analysis of the measurement system the true value of each coating thickness was determined with microscope and the results with related arithmetic means $(\bar{x})$ and standard deviations $(s)$ are given in Table 1. 


\begin{tabular}{l|c|c|c|cc}
\hline \multicolumn{7}{c}{ Measurements, $\boldsymbol{\mu m}$} \\
\multicolumn{1}{c}{$\mathbf{1}$} & $\mathbf{2}$ & $\mathbf{3}$ & $\bar{x}$ & $\mathbf{s}$ \\
\hline PART 1 & 34,90 & 41,17 & 43,23 & $\mathbf{3 9 , 7 7}$ & $\mathbf{4 , 3 4}$ \\
\hline PART 2 & 84,71 & 88,44 & 90,13 & $\mathbf{8 7 , 9 9}$ & $\mathbf{2 , 3 8}$ \\
\hline PART 3 & 168,92 & 153,18 & 141,93 & $\mathbf{1 5 4 , 6 7}$ & $\mathbf{1 3 , 5 6}$ \\
\hline
\end{tabular}

Table 1. Coating thickness true value

\section{Measurement results and statistical analysis}

Measurement results for each coating thickness are given in Table 2. The thickness was measured at 5 different measurement spot (T1, T2, T3, T4 and T5) and for each measurement spot measurement was repeated 3 times.

\begin{tabular}{|c|c|c|c|c|c|c|c|}
\hline \multicolumn{4}{|c|}{ Measurement system 1} & \multicolumn{4}{|c|}{ Measurement system 2} \\
\hline $\begin{array}{l}\text { Measurement } \\
\text { spot }\end{array}$ & $\begin{array}{l}\text { PART 1, } \\
\text { mm }\end{array}$ & $\begin{array}{c}\text { PART 2, } \\
\text { mm }\end{array}$ & $\begin{array}{l}\text { PART 3, } \\
\text { mm }\end{array}$ & $\begin{array}{c}\text { Measurement } \\
\text { spot }\end{array}$ & $\begin{array}{l}\text { PART 1, } \\
\text { mm }\end{array}$ & $\begin{array}{l}\text { PART 2, } \\
\mathrm{mm}\end{array}$ & $\begin{array}{c}\text { PART 3., } \\
\text { mm }\end{array}$ \\
\hline \multirow{3}{*}{ T1 } & 0,03 & 0,073 & 0,158 & \multirow{3}{*}{ T1 } & 0,0375 & 0,088 & 0,1765 \\
\hline & 0,03 & 0,073 & 0,157 & & 0,0372 & 0,088 & 0,1765 \\
\hline & 0,029 & 0,073 & 0,155 & & 0,0362 & 0,0887 & 0,1767 \\
\hline \multirow{3}{*}{$\mathbf{T} 2$} & 0,031 & 0,069 & 0,141 & \multirow{3}{*}{$\mathbf{T 2}$} & 0,0381 & 0,083 & 0,15 \\
\hline & 0,03 & 0,069 & 0,144 & & 0,0371 & 0,0837 & 0,148 \\
\hline & 0,031 & 0,07 & 0,143 & & 0,0383 & 0,0828 & 0,148 \\
\hline \multirow{3}{*}{$\mathbf{T 3}$} & 0,028 & 0,073 & 0,139 & \multirow{3}{*}{$\mathbf{T 3}$} & 0,0342 & 0,086 & 0,147 \\
\hline & 0,03 & 0,072 & 0,14 & & 0,0339 & 0,0866 & 0,146 \\
\hline & 0,027 & 0,072 & 0,139 & & 0,0338 & 0,855 & 0,147 \\
\hline \multirow{3}{*}{ T4 } & 0,031 & 0,074 & 0,132 & \multirow{3}{*}{ T4 } & 0,037 & 0,0874 & 0,138 \\
\hline & 0,03 & 0,074 & 0,133 & & 0,037 & 0,0872 & 0,138 \\
\hline & 0,03 & 0,075 & 0,133 & & 0,0368 & 0,087 & 0,139 \\
\hline \multirow{3}{*}{ T5 } & 0,03 & 0,072 & 0,128 & \multirow{3}{*}{ T5 } & 0,0376 & 0,0853 & 0,133 \\
\hline & 0,031 & 0,072 & 0,128 & & 0,0378 & 0,0851 & 0,133 \\
\hline & 0,03 & 0,072 & 0,128 & & 0,0376 & 0,0854 & 0,133 \\
\hline
\end{tabular}

Table 2. Coating thickness measurement results

For the purpose of determination of significance of the effects the ANOVA method was used. The potential influencing factors which were used in analysis are Coating thickness, Measurement system and Measurement spot.

\begin{tabular}{|c|c|c|c|c|c|}
\hline \multirow[b]{2}{*}{ Effect } & \multicolumn{5}{|c|}{$\begin{array}{l}\text { ANOVA table } \\
\text { Effective hypothesis decomposition }\end{array}$} \\
\hline & \begin{tabular}{|l|} 
Degr. of \\
Freedom
\end{tabular} & $\begin{array}{l}\text { Difference, } \mathrm{mm} \\
\text { SS }\end{array}$ & $\begin{array}{c}\text { Difference, } \mathrm{mm} \\
\text { MS }\end{array}$ & $\begin{array}{c}\text { Difference, } \mathrm{mm} \\
\mathrm{F} \\
\end{array}$ & $\begin{array}{c}\text { Difference, } \mathrm{mm} \\
\mathrm{p}\end{array}$ \\
\hline Intercept & 1 & 0.002443 & 0.002443 & 66.27748 & 0.000000 \\
\hline Coating thickness & 2 & 0.000134 & 0.000067 & 1.81624 & 0.186189 \\
\hline Measurement system & 1 & 0.000601 & 0.000601 & 16.30519 & 0.000550 \\
\hline Measurement spot & 4 & 0.000361 & 0.000090 & 2.44893 & 0.076375 \\
\hline Error & 22 & 0.000811 & 0.000037 & & \\
\hline Total & 29 & 0.001907 & & & \\
\hline
\end{tabular}

Table 3. ANOVA analysis of the measurement difference

Response variable was the difference to the true value measured by microscope. The results provided in table 3 shows that there is only one significant factor ("Measurement system" with $\mathrm{p}<0,001$ ). 


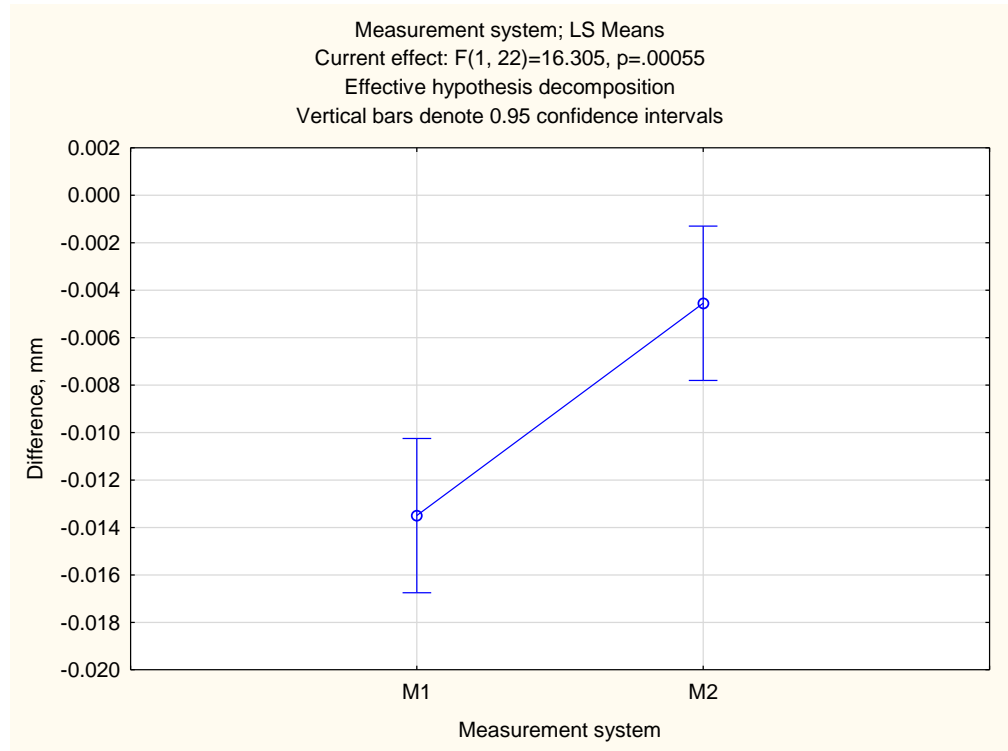

Fig. 2. 95\%CI plot of categorical factor measurement system

The Figure 2 shows that $2^{\text {st }}$ measurement system has better accuracy, while $1^{\text {st }}$ one has statistically larger difference to the true value. The statistical analysis also shows that there is no statistically significant difference between measurement spots using usual confidence level of 95\% (Figure 3).

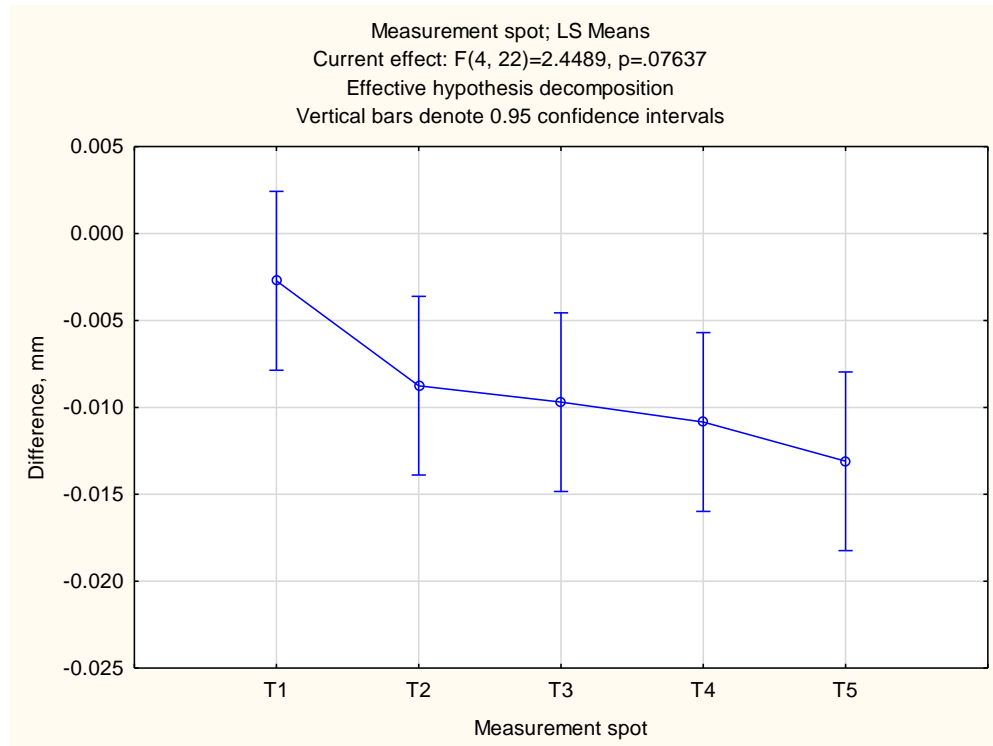

Fig. 3. 95\%CI plot of categorical factor measurement spot 


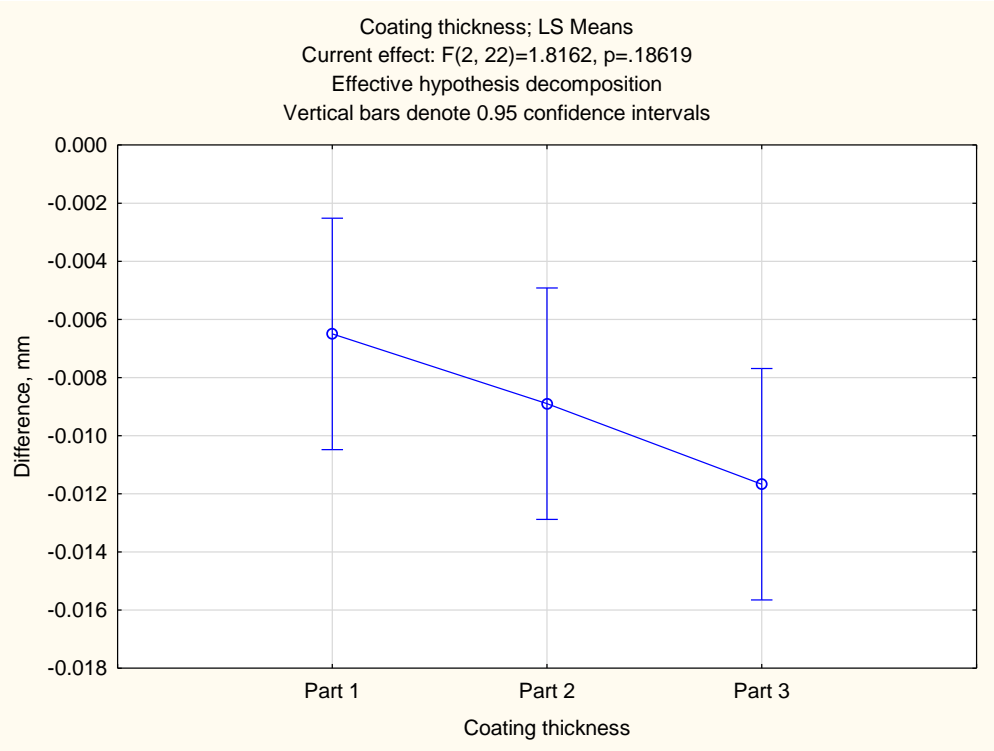

Fig. 4. 95\% CI plot of categorical factor coating thickness

In order to complement the analysis, the Figure 4 shows the confidence interval plots of factor coating thickness. For the figure it is obvious that there is no significant difference in measurement uncertainty measuring the parts with various thickness coating.

To assure the reliability of the used method the analysis of the residuals was also performed (Figure 5). From the residual analysis it can be concluded that there are no uncontrolled factors which has a significant impact on measurement process. The residuals are normally distributed and can be accepted as random noise (white noise).

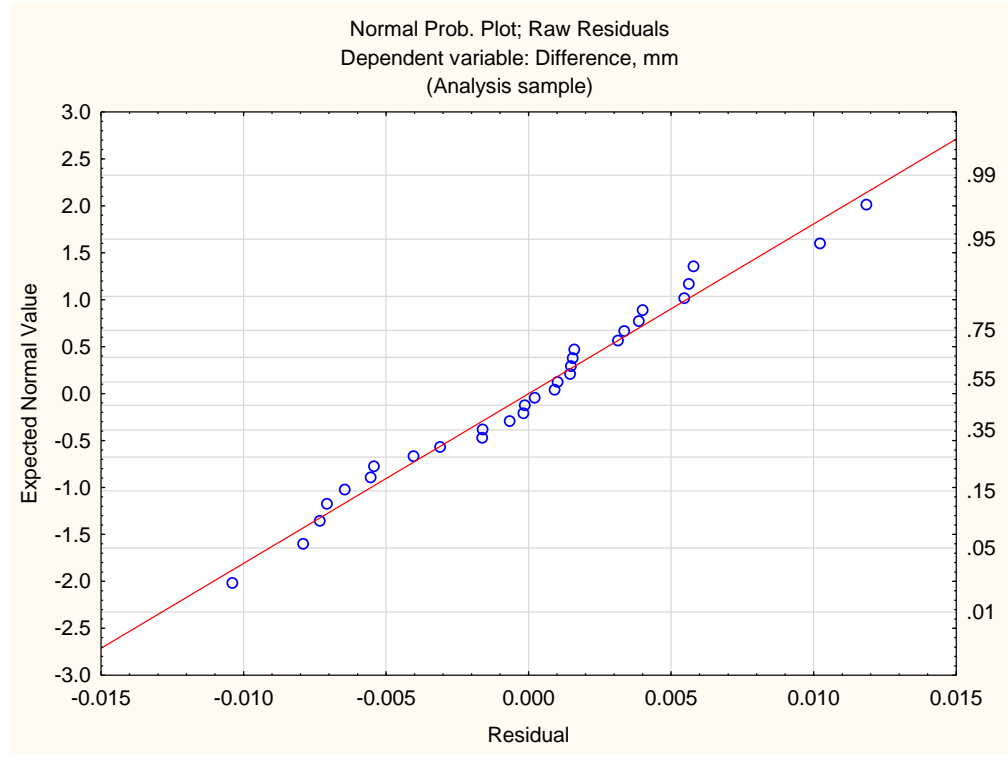

Fig. 5. Normal probability plot of residuals

\section{Conclusion}

Eddy current is a widely applicable non-destructive testing for the coating thickness measurement. In that sense, eddy current measurement is quantitative method and measurement results should never be reported without reporting measurement uncertainty. Unfortunately, personnel that perform measurements usually omit to display the measurement results with associated measurement uncertainty. For uncertainty estimation it is essential to detect and keep under control all influential factors in any measurement system. In this paper it was investigated influence of coating thickness, measurement system and measurement spots on coating thickness measurement results by using eddy current measurement method. Obtained results were analysed and commented regarding the ANOVA method. 
Measurement comparisons of two measurement system is based on reference values of coating thicknesses that are determined by means of image analysis software for metallographic specimens.

By comparison it was established that measurement system has impact on measurement uncertainty and more attention should be paid on measurement system accuracy. In this paper three influential factors on measurement results was selected and their effect significance were analysed. Through the conducted experiments the ANOVA analysis shows that there is no statistically significant difference between measurement spots which indicates appropriate coating process applying. Also, the presented analysis shows that there is no significant difference in measurement uncertainty measuring the parts regarding various thickness coating. But the significant factor is measurement system which has significant impact on the resulting measurement.

Furthermore, with the scope to assure the reliability of experimental setup and analysis the residual analysis was conducted. From the mentioned analysis it can be concluded that there are no uncontrolled factors which has a significant impact on measurement process and the ANOVA model is considered valid.

Conducted experiments relates to the selected measurement system and their parameters. By changing any parameters in measurement system impact on measurement result could be changed with different contribution on measurement uncertainty. With the scope to estimate the measurement uncertainty of coating thickness measurement results by using eddy current method of selected system all factors that influence accuracy and precision should be analysed. For the further research impact of individual factors and their synergy impact should be quantified.

\section{References}

[1] Zaujec, R.; Vopat, T.; Simna, V. \& Jurina, F. (2018). Coating of Cutting Tool and CAM Milling Strategy Influence on the Tool Wear and Surface Roughness, Proceedings of the $29^{\text {th }}$ International DAAAM Symposium "Intelligent Manufacturing \& Automation", 24 th $-27^{\text {th }}$ October 2018, Zadar, Croatia, ISSN 1726-9679, ISBN 978-3-902734-204, Katalinić, B. (Ed.), DAAAM International Vienna, Vienna, Austria.

[2] Fotovvati, B.; Namdari, N. \& Dehghanghadikolaei, A. (2019). On Coating Techniques for Surface Protection: A Review, Journal of Manufacturing and Materials processing, Vol.3, No.1, (March 2019), pp 1-22, ISSN 2504-4494.

[3] Kubatova, D. \& Melichar, M. (2018). Uncertainty of Surface Measurement. Proceedings of the 29th International DAAAM Symposium "Intelligent Manufacturing \& Automation", 24-27th October 2018, Zadar, Croatia, ISSN 1726-9679, ISBN 978-3-902734-20-4, Katalinić, B. (Ed.), DAAAM International Vienna, Vienna, Austria.

[4] Keran, Z.; Mihaljević, M.; Runje, B. \& Markučič, D. (2017). Ultrasonic testing of grain distortion direction incold formed aluminium profile, Achive of Civila and Mechanical Engineering, Vol. 17, No. 2, pp 375-381, ISSN 16449665.

[5] Mihaljević, M. (2015). Measurement uncertainty estimation of the ultrasonic thickness measurement. Ph.D. Dissertation, Quality Department, University of Zagreb, Zagreb, Croatia.

[6] Willcox, M. \& Downes, G. (2006). A review of common nondestructive tests - Assessing each process, its tools, advantages, and disadvantages. Available from: https://www.thefabricator.com/article/testingmeasuring/a-reviewof-common-nondestructive-tests. Accessed: 2019-09-18.

[7] Yin, W. \& Peyton, A.J. (2017). Thickness measurement of non-magnetic plates using multi-frequency eddy current sensors. NDT\&E International, Vol. 40, No.1, (January 2017), pp 43-48, 2007. ISSN 0963-8695.

[8] JCGM 101:2008, Evaluation of measurement data - Supplement 1 to the "Guide to the expression of uncertainty in measurement"- Propagation of distributions using a Monte Carlo method

[9] Montgomery, D. \& Runger, G. (2002). Applied Statistics and Probability for Engineers, John Wiley \& Sons, Inc. third edition, ISBN 0-471-20454-4, United Stated of America. 